\title{
Alteração do metabolismo respiratório em rabanetes minimamente processados
}

\author{
Alteration of the respiratory metabolism in whole and fresh cut radishes
}

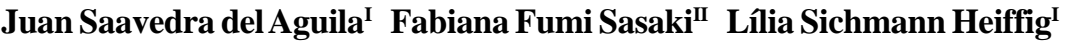 \\ Edwin Moisés Marcos Ortega ${ }^{\mathrm{III}}$ Angelo Pedro Jacomino ${ }^{\mathrm{I}}$ Ricardo Alfredo Kluge ${ }^{\mathrm{II}}$
}

\begin{abstract}
- NOTA -
RESUMO

O presente experimento visou a determinar a taxa respiratória e a produção de etileno de raízes de rabanete

$170.32 \mathrm{~mL} \mathrm{CO}_{2} \mathrm{~kg}^{-1} \mathrm{~h}^{-1}$, respectively. On the $10^{\text {th }}$ day of storage, fresh cut radishes showed respiratory rate $149 \%$ higher than whole radishes. The minimal processing operations, mainly the cut, enhanced the respiratory rate.
\end{abstract} minimamente processadas em comparação ao produto nãoprocessado, durante armazenamento refrigerado. As taxas foram determinadas durante as 4 primeiras horas após o processamento e diariamente, por 10 dias de armazenamento a $5^{\circ} \mathrm{C}\left( \pm 1^{\circ} \mathrm{C}\right)$ e $90 \%$ ( $\left.\pm 5 \%\right)$ UR. Raízes de rabanete inteiras apresentaram taxa respiratória de 40,61 $\mathrm{mL} \mathrm{CO}_{2} \mathrm{~kg}^{-1} \mathrm{~h}^{-1}$, enquanto que as raízes em retalhos apresentaram até $93,90 \mathrm{~mL}$ $\mathrm{CO}_{2} \mathrm{~kg}^{-1} \mathrm{~h}^{-1}$ após 4 horas do processamento. As raízes de rabanete inteiras e as minimamente processadas apresentaram pico respiratório no 2 o dia de armazenamento, com 99,27 e $170,32 \mathrm{~mL} \mathrm{CO}_{2} \mathrm{~kg}^{-1} \mathrm{~h}^{-1}$, respectivamente. No $10^{\circ}$ dia de armazenamento, as raízes de rabanete minimamente processadas apresentaram taxa de respiração $149 \%$ superior à verificada nas raízes inteiras. As operações de processamento mínimo, principalmente o corte, elevaram a taxa respiratória das raízes de rabanete.

Palavras-chave: Raphanus sativus L., armazenamento refrigerado, pós-colheita.

\section{ABSTRACT}

The present experiment was aimed at determining the respiratory rate and ethylene production of fresh cut radish and whole radish during cold storage. The rates were evaluated during the first 4 hours after processing and daily, during 10 days at $5^{\circ} \mathrm{C}\left( \pm 1^{\circ} \mathrm{C}\right)$ and $90 \%( \pm 5 \%) \mathrm{RH}$. Radishes not processed presented lower respiratory rate $\left(40.61 \mathrm{~mL} \mathrm{CO} \mathrm{Cg}^{-1} \mathrm{~h}^{-1}\right)$ if compared to shredded radishes (93.90mL CO $\mathrm{kg}^{-1} \mathrm{~h}^{-1}$ ) 4 hours after processing. Whole and fresh cut radishes showed the highest respiratory rate in the $2^{\text {nd }}$ day of storage with 99.27 and
Key words: Raphanus sativus L., cold storage, postharvest.

Na busca de obter uma vida saudável, as pessoas estão mudando seus hábitos alimentícios, acrescentando, ao seu dia a dia, o consumo de vegetais de diferentes espécies e com propriedades nutricionais complementares. Além disso, o ritmo de vida atual obriga a se destinar cada vez menos tempo às atividades de preparo das refeições. Assim sendo, o processamento mínimo de vegetais surge como uma resposta tecnológica a esta nova necessidade de um setor da sociedade.

Uma característica da cultura do rabanete é poder ser usada como cultura de rápido retorno econômico, entre outras de ciclo mais longo, com épocas definidas de plantio, pois, além de ser relativamente rústica, apresenta ciclo muito curto, de cerca de 30 dias (MINAMI \& NETTO, 1997). As raízes de rabanete estão ganhando mercado no comércio de produtos minimamente processados, porém pouco se conhece do seu comportamento fisiológico depois de embaladas.

Este experimento visou a determinar a taxa respiratória e a produção de etileno de raízes de

\footnotetext{
'Departamento de Produção Vegetal, Universidade de São Paulo, Escola Superior de Agricultura “Luiz de Queiroz” (USP/ESALQ), CP 9, 13418-900 Piracicaba, SP, Brasil. E-mail: jsaguila@esalq.usp.br. Autor para correspondência.

"Departamento de Ciências Biológicas, USP/ESALQ, CP 9, 13418-900, Piracicaba, SP, Brasil.

IIIDepartamento de Ciências Exatas, USP/ESALQ, CP 9, 13418-900, Piracicaba, SP, Brasil.
} 
rabanete minimamente processadas durante o armazenamento refrigerado.

Maços de rabanete da variedade "Crimson gigante”, colhidos na região de Piracicaba-SP, no mês de julho, passaram pelas seguintes operações de processamento mínimo: a) Seleção 1 e Lavagem. b) Sanitização 1: as raízes foram submersas por 10 minutos em água contendo $200 \mathrm{mg} \mathrm{L}^{-1}$ de cloro ativo. O sanitizante utilizado foi o SUMAVEG, que contém como princípio ativo o Dicloro-S-Triazinatriona Sódica Diidratada e é fabricado pela Diversey Lever-Indústrias Gessy Lever Ltda. O material sanitizado e escorrido foi imediatamente levado para a câmara fria a uma temperatura de $10^{\circ} \mathrm{C}$. c) Preparo do material: foram separados dois lotes, sendo que um sofreu apenas a limpeza, sendo retiradas as partes basais e apicais das raízes do rabanete, e o outro foi minimamente processado em retalhos de $2 \mathrm{~cm}$ x $2 \mathrm{~mm}$ de largura e espessura. As raízes separadas para o processamento foram cortadas em processadora industrial Robot Coupe $^{\circledR}$, CL50 version D. d) Enxágüe 1: após o corte em retalhos, o material foi acondicionado em saco de nylon, e submerso em água destilada a $5^{\circ} \mathrm{C}$. e) Sanitização 2: ambos os lotes de raízes de rabanete foram submersos em água destilada contendo 200mg $\mathrm{L}^{-1}$ de cloro ativo (SUMAVEG), por 3 minutos. $f$ ) Enxágüe 2: depois de sanitizadas, as raízes de rabanete foram submersas em água destilada a $5^{\circ} \mathrm{C}$, contendo $3 \mathrm{mg} \mathrm{L} \mathrm{L}^{-1}$ de cloro ativo, por um minuto, retirando-se o excesso de cloro. g) Retirada do excesso de água: Escorrimento: as raízes de rabanete não processadas foram colocadas em um escorredor para a saída do excesso de água. Centrifugação: O saco de nylon contendo as raízes de rabanete processadas foi introduzido em centrífuga por 1 minuto (rotação média de $800 \mathrm{~g}$ ), eliminando-se o excesso de água. h) Seleção 2: foram descartadas as raízes de rabanete nãopadronizadas para a comercialização. i) Embalagem: foram pesadas aproximadamente $130 \mathrm{~g}$ de raiz de rabanete minimamente processada ou não, sendo colocadas em frascos de vidro de $580 \mathrm{~mL}$, cuja tampa fora perfurada e coberta com silicone (septo). No total, foram preparados 10 frascos para cada tratamento (minimamente processado e inteiro). j) Armazenamento: os frascos foram armazenados na câmara fria, a $5^{\circ} \mathrm{C}\left( \pm 1^{\circ} \mathrm{C}\right)$ e $90 \%( \pm 5 \%) \mathrm{UR}$, por um período de 10 dias.

Para a determinação da taxa respiratória através do septo, foi retirada uma alíquota $(1 \mathrm{~mL})$ da atmosfera interna dos frascos de vidro herméticos. Essas amostras de gases foram injetadas em um cromatógrafo a gás (marca Thermoffinigan, modelo Trace 2000 GC) equipado com detector de ionização de chama (FID), com coluna Porapack N, de 2m de comprimento. O hidrogênio foi utilizado como gás de arraste a $40 \mathrm{~mL} \mathrm{~min}^{-1}$. As temperaturas mantidas no aparelho foram de $100^{\circ} \mathrm{C}$ para a coluna, de $100^{\circ} \mathrm{C}$ no injetor, de $250^{\circ} \mathrm{C}$ no detector e, para o caso do $\mathrm{CO}_{2}$, a $350^{\circ} \mathrm{C}$ no metanador.

Após uma hora do processamento, a cada uma hora, durante 4 horas, foi retirada uma amostra da composição gasosa do interior dos frascos e mediu-se a evolução de $\mathrm{CO}_{2}$. A primeira leitura correspondeu ao tempo zero. Posteriormente, as leituras foram realizadas todos os dias, durante 10 dias, para os dois tratamentos. Imediatamente após cada leitura, os frascos eram abertos, tendo suas tampas substituídas por um filme de policloreto de vinila (PVC) de $14 \mu \mathrm{m}$ de espessura. Os resultados de taxa respiratória foram expressos em $\mathrm{mL} \mathrm{CO} \mathrm{kg}^{-1} \mathrm{~h}^{-1}$. Para a determinação da produção de etileno, foram utilizadas as mesmas amostras e os resultados expressos em $\mu \mathrm{L} \mathrm{C}_{2} \mathrm{H}_{4} \mathrm{~kg}^{-1} \mathrm{~h}^{-1}$.

O delineamento utilizado foi o inteiramente casualizado, com 10 repetições para cada tratamento, em diferentes tempos. Os dados foram submetidos à análise de medidas repetidas, sendo que a comparação das médias entre os tratamentos foi feita univariadamente (para cada tempo em separado), pelo teste de Tukey a 5\% de probabilidade.

O processamento mínimo causou alteração no metabolismo respiratório das raízes de rabanete, sendo que a taxa respiratória de raízes de rabanete minimamente processadas foi superior à verificada nas raízes não-processadas. Entretanto, para ambos os tratamentos, houve elevação da respiração durante as quatro primeiras horas após o processamento (Figura 1). Durante o armazenamento, foram obtidos picos de respiração com posterior decréscimo em ambos os tratamentos (Figura 2).

Os picos respiratórios observados para as raízes de rabanete minimamente processadas e inteiras advêm do estresse provocado pelo corte. Este provoca perda da compartimentação celular e, com isso, os substratos do metabolismo respiratório têm maior contato com os complexos enzimáticos, resultando num aumento da taxa respiratória (PURVIS, 1997).

As raízes de rabanete inteiras apresentaram a menor taxa respiratória durante o período avaliado, atingindo valores de 40,61mL $\mathrm{CO}_{2} \mathrm{~kg}^{-1} \mathrm{~h}^{-1}$ depois de quatro horas (Figura 1). Por outro lado, as raízes minimamente processadas apresentaram elevação na atividade respiratória logo após o processamento mínimo, atingindo 93,90 $\mathrm{mL} \mathrm{CO}_{2} \mathrm{~kg}^{-1} \mathrm{~h}^{-1}$ depois de quatro horas. MORETTI et al. (2000), trabalhando com pimentões, encontraram elevação significativa da atividade respiratória logo após o processamento 


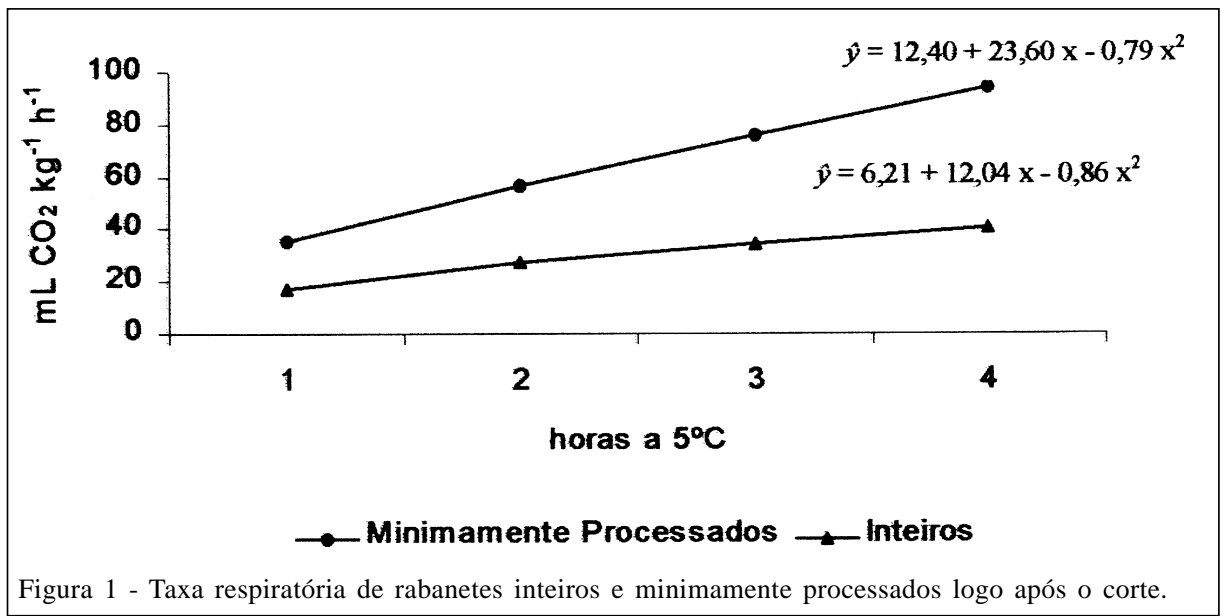

mínimo, sendo esta três vezes maior do que em frutos intactos armazenados sob as mesmas condições $\left(2^{\circ} \mathrm{C}\right)$.

No primeiro dia de armazenamento, os rabanetes inteiros produziram $38,78 \mathrm{~mL} \mathrm{CO}_{2} \mathrm{~kg}^{-1} \mathrm{~h}^{-1}$, sendo este valor significativamente menor que aos encontrados para os rabanetes minimamente processados $\left(92,53 \mathrm{~mL} \mathrm{CO}_{2} \mathrm{~kg}^{-1} \mathrm{~h}^{-1}\right)$. No último dia de armazenamento $\left(10^{\circ} \mathrm{dia}\right)$, os rabanetes inteiros apresentaram, também, a menor taxa respiratória $\left(28,23 \mathrm{~mL} \mathrm{CO}_{2} \mathrm{~kg}^{-1} \mathrm{~h}^{-1}\right)$, enquanto que os minimamente processados apresentaram a maior taxa de produção de gás carbônico $\left(70,35 \mathrm{~mL} \mathrm{CO}_{2} \mathrm{~kg}^{-1} \mathrm{~h}^{-1}\right)$.

Durante todos os dias de armazenamento, as produções de gás carbônico dos rabanetes inteiros foram significativamente menores que as observadas nos rabanetes minimamente processados, sendo que, no $10^{\circ}$ dia de armazenamento, os rabanetes minimamente processados apresentaram uma taxa respiratória 149\% superior à dos rabanetes inteiros. Produção elevada de $\mathrm{CO}_{2}$, imediatamente após o corte e decréscimo desta durante o período de armazenamento, também foram verificadas por VITTI et al. (2003), em experimentos com beterrabas minimamente processadas armazenadas a $5^{\circ} \mathrm{C}$.

Em nenhum dos dois tratamentos foram detectadas produções de etileno, indicando uma baixa produção deste gás, menor que $0,1 \mu \mathrm{L} \mathrm{L}^{-1} \mathrm{C}_{2} \mathrm{H}_{4}$, limite mínimo de detecção de etileno pelo cromatógrafo utilizado.

No presente trabalho, verificou-se que raízes de rabanete minimamente processadas apresentam aumento na taxa respiratória durante o armazenamento refrigerado.

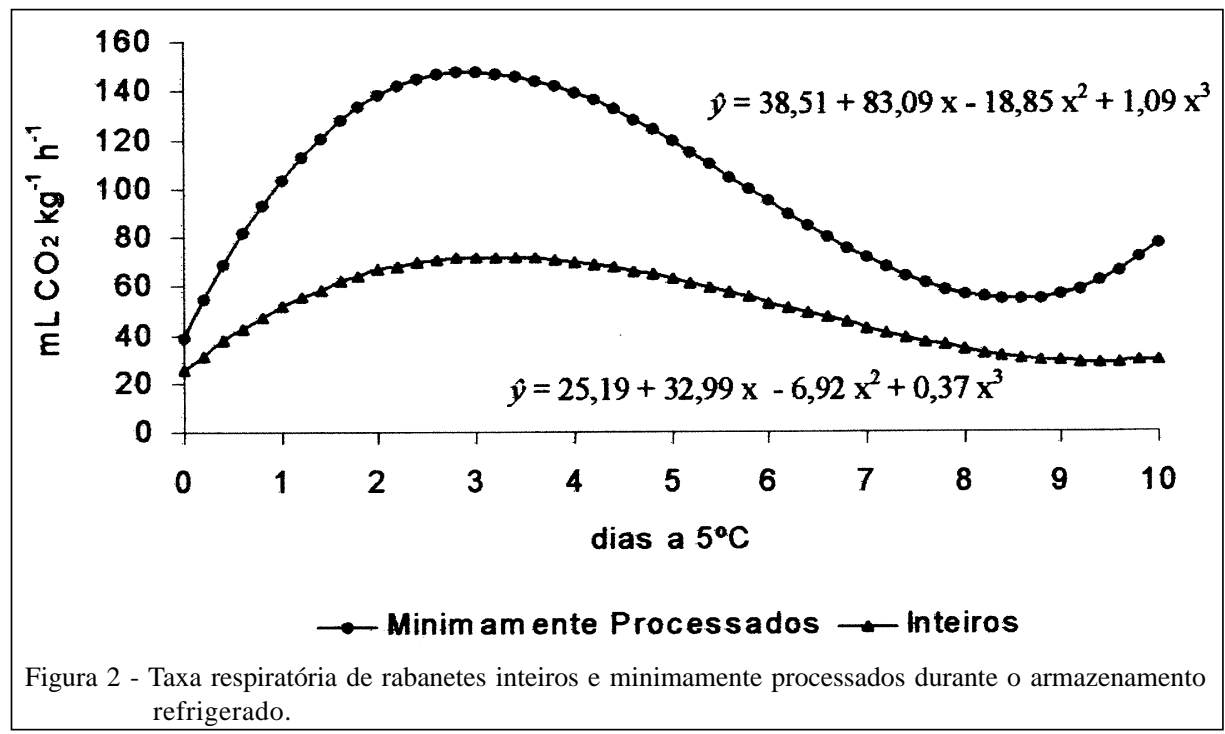

Ciência Rural, v.37, n.2, mar-abr, 2007. 


\section{AGRADECIMENTOS}

À Fundação de Amparo à Pesquisa de São Paulo (FAPESP) pela bolsa do Doutorado do primeiro e do segundo autor; e ao Conselho Nacional de Desenvolvimento Científico e Tecnológico (CNPq), pela bolsa de Doutorado do terceiro autor e pelas bolsas de produtividade em Pesquisa do quinto e do sexto autor.

\section{REFERÊNCIAS}

MINAMI, K.; NETTO, J.T. Rabanete: cultura rápida, para temperaturas amenas e solos areno-argilosos. Piracicaba: ESALQ, 1997. 27p. (Série Produtor Rural, 4).
MORETTI, C.L. et al. Alteração no metabolismo respiratório de pimentões em função do processamento mínimo e da temperatura de armazenamento. Horticultura Brasileira, v.18, n.3, p.331-332, 2000.

PURVIS, A.C. The role of adaptive enzymes in carbohydrates oxidation by stressed and senescing plant tissues. HortScience, v.32, n.7, p.1165-1168, 1997.

VITTI, M.C.D. et al. Comportamento da beterraba minimamente processada em diferentes espessuras de corte. Horticultura Brasileira, v.21, n.4, p.623-626, 2003. 